\title{
Epistemologia e comunicabilidade: as crises das ciências, ante a perspectiva da centralidade do conceito de comunicação
}

\author{
Epistemology and communicability: the crisis of the sciences, in view of the \\ centrality of the concept of communication \\ Luiz Signates \\ (signates@gmail.com $)^{1}$ \\ http://dx.doi.org/10.5216/cei.v15i2.24573
}

\begin{abstract}
Resumo
Trata este texto de uma análise epistemológica da ciência, em direção à perspectiva da centralidade do conceito de comunicação. Inicialmente, efetua uma breve digressão sobre três crises das ciências: a crise da verdade, a crise das disciplinas e a crise social da ciência. Em seguida, avalia o estágio em que se encontra o debate teórico-epistemológico do campo científico da comunicação e posiciona o conceito de comunicação como aspecto central do problema epistemológico das ciências, no mundo contemporâneo.
\end{abstract}

Palavras-chaves: Epistemologia da comunicação. Crise da ciência. Ciência da comunicação.

\begin{abstract}
This text comes from an epistemological analysis of science, toward the perspective of the centrality of the concept of communication. Initially, makes a brief digression on three crises of science: the crisis of truth, the crisis of the disciplines and the crisis of the social sciences. Then evaluates the state of the art on the theoretical-epistemological debate of the communications scientific field and places the concept of communication as a central aspect of the epistemological problem of science in the contemporary world.
\end{abstract}

Keywords: Epistemology of communication. Crisis of science. Communication science.

\section{Introdução}

Este texto surge de um esforço intelectual que busca debater a questão da fragilidade epistemológica da comunicação e, por consequência, o perfil exógeno das teorizações produzidas em nossa área. Fazemos parte de uma disciplina que se pretende científica, mas não possui as grandes teorias nas quais se basear e, por esta razão, acolhe as teorizações dos mais diversos ramos das ciências sociais, humanas e da linguagem, de modo tal que o objeto específico - a comunicação - é sempre percebido de forma lateral, acondicionado a um olhar que termina por não percebê-lo.

1 Professor adjunto da Universidade Federal de Goiás e da Pontifícia Universidade Católica de Goiás. Membro permanente do corpo docente do PPG em Comunicação da UFG, linha de pesquisa Mídia e Cultura. Pós-doutor pela Unisinos e Doutor pela ECA-USP. Coordenador de Goiás do Procad240/2007 "Crítica Epistemológica”.

Comum. \& Inf., v. 15, n. 2, p. 133-148, jul./dez. 2012 
O sintoma central dessa fragilidade tem se revelado nos consecutivos trabalhos produzidos por Braga, para quem os textos de comunicação sempre tendem a deixar como lacuna comum justamente o que deveria ser central ou, pelo menos, o fundamento minimamente resolvido: a definição do que seja o próprio conceito de comunicação. Um dos primeiros estudiosos que perceberam este problema foi Albuquerque (2002), que identificou a presença da comunicação em várias ciências sociais, mas, em nenhuma delas, a noção de comunicação ocupava lugar de centralidade.

\begin{abstract}
... a comunicação humana - entendida em sua dimensão mais genérica - constitui um objeto comum a todas as ciências sociais. Por outro lado, é bastante evidente que, nos casos citados, a comunicação constitui tão somente o pano de fundo da investigação e não o problema principal. Cabe perguntar, portanto: que tipo de fenômeno suscitou o desenvolvimento da comunicação como um objeto de investigação de direito próprio, antes que como um pano de fundo para outros objetos teóricos? (ALBUQUERQUE, 2002, p. 2).
\end{abstract}

Este tipo de preocupação levou José Luiz Braga a propor que se fizesse, sobre os estudos da área da comunicação, o "desentranhamento" do que é especificamente comunicacional nestes estudos (Braga, 2004). O esforço de Braga tem sido, então, o de formular perguntas e, ao fazê-lo, ele tem produzido princípios de teorizações que podem ser consideradas fundantes, já que é de indagações que as teorias são de fato feitas. Teoria é o pensamento sistematizado que surge de indagações e o que produz e condiciona a pertinência delas. Não são as explicações, e sim as perguntas, aquilo que interessa nas teorias.

Inicialmente, eu acreditava que a fragilidade epistemológica da comunicação se devia à ausência de uma teoria de sociedade que levasse em alta consideração o fato da comunicação. Num texto, elaborado logo após o doutoramento, eque fundamentou meu projeto de pós-doutorado, sintomaticamente intitulado "O problema não é só nosso: Um estudo sobre a fragilidade epistemológica das teorias sociais para dar conta da problemática da comunicação" (SIGNATES, 2001), eu parti da ideia de que a formulação de qualquer teoria da comunicação tinha que obrigatoriamente se basear numa pressuposição teórica a respeito da sociedade e clamei por uma teorização de sociedade que contivesse os alicerces para a construção teórica da comunicação.

De certa forma, esse modo de pensar eu trouxera do doutoramento, quando me debrucei sobre a última grande teoria de sociedade disponível nas ciências sociais - a Teoria da Ação Comunicativa, de Habermas (1982) - e, reconhecendo sua grande atualidade, busquei criticá-la por sua ausência gritante: na sociedade habermasiana da comunicação, não havia também, como faltou em Marx e Weber, a teorização dos dispositivos midiáticos. Habermas, como bem criticou 
Thompson (2002), restringiu o conceito de comunicação à relação face-a-face, deixando de perceber que a mediação tecnológica produz e condiciona novos tipos de relação social, exigindo, por isso mesmo, falar-se de outra sociedade ou de outro modo de estar em sociedade.

A apreensão de que o problema está em outras disciplinas científicas, contudo, cedo revelouse enganosa. Se alguém for capaz de construir algum edifício teórico próprio da comunicação, esse intelectual será alguém inscrito até a medula neste campo, informado pelas preocupações específicas que este campo gera, e não outrem, cujas formação e preocupações não têm, desde o princípio, a comunicação como fundamento ou questão-problema básica. Foi então que desloqueime da busca por uma teoria sociológica que fundamentasse a comunicação - ainda um olhar externo ao campo, hoje o percebo - para um esforço por partir o olhar da própria comunicação, em direção aos diversos conceitos teóricos. Em outras palavras, abandonei a exigência da centralidade de uma teoria orientada aresolver o problema da comunicação, para tentar encarar de frente a necessidade da centralidade da comunicação para o desenvolvimento de teorias que possam pelo menos indicar os problemas da contemporaneidade.

O presente trabalho segue nesta linha, buscando um diferencial específico: o enfrentamento do problema epistemológico das ciências. Ou seja, a problemática que se busca discutir aqui é a de que o debate epistemológico da comunicação deve, antes de mais nada, considerar a centralidade da comunicação, para ser feito, caso contrário, estaremos incorrendo em contradição performática: fazendo com o debate epistemológico aquilo que, nele próprio, acusamos as teorias analisadas de fazer, isto é, de debater a comunicação a partir de um prisma que lhe seja externo, e não nos seus próprios termos. Busca-se, então, neste trabalho, os pródromos do que pode ser uma epistemologia comunicativa da comunicação.

\section{0 quadro das crises das ciências}

O debate epistemológico que ocorre hoje no campo da comunicação no Brasil coloca-nos no centro de uma efervescência que é preciso explicitar: a das crises 2 das ciências como um todo.Não 2 A ideia de situar no plural - tanto do vocábulo "crise", quanto do "ciência" - o que tem sido chamado de "crise das
ciências" ou "crise da ciência" visa demonstrar que os questionamentos não são unificados, nem se referem a toda e
qualquer ciência. Tanto isso é verdade que o que, por analogia, poderia ser denominado de crise da ciência da

Comum. \& Inf., v. 15, n. 2, p. 133-148, jul./dez. 2012 
é de hoje que se fala em crise, nas ciências, mesmo que se reconheça ser, desde o espanto ante a revolução industrial e, posteriormente, a revolução tecnológica, talvez o campo de produção cultural de maior prestígio no mundo contemporâneo. Mesmo que articulada primordialmente pela dúvida - ou pela falseabilidade, como queria Popper -, certamente não existe nenhum campo social nos dias atuais que tenha maior capacidade de dizer a verdade e maior credibilidade nesse sentido, que o campo científico. Categorizar como ciência um sistema qualquer de pensamento significa garantir para ele uma posição de elevado prestígio, na hierarquia dos saberes em circulação no mundo contemporâneo.

A ciência no mundo contemporâneo vive uma série de crises e questionamentos, decorrentes dos mais diferentes fatores. Para o ponto de vista deste ensaio, evidenciaremos apenas três, das principais crises que, há décadas, filósofos, epistemólogos e cientistas - sobretudo os oriundos das ciências humanas e sociais - têm denunciado: a crise da verdade, a crise das especializações e a crise social. Do conjunto dessas três espécies de crise, buscaremos pensar os limites e possibilidades da ciência da comunicação, que, a nosso ver, desenvolve uma crise que lhe é toda própria, sendo, talvez, uma anticrise, ou uma crise contra as crises, a partir da qual enuncia-se uma rede de possibilidades, que este ensaio pretende trabalhar.

Primeiro, vive a ciência a crise da verdade. O problema da verdade era a grande preocupação posicionada no debate de Sócrates e Platão com os sofistas - os comunicadores da Grécia antiga -, que o mestre de Aristóteles criticava como impostores, para quem a retórica não era outra coisa, senão uma técnica de convencimento sem compromisso com a verdade. O brado contra o mero funcionalismo retórico significava uma forte proposição, que se seguiu depois com o Estagirita, de que não há argumento melhor e mais convincente, tanto do ponto de vista técnico, quanto do ético, do que a verdade. Na busca pela prova da verdade, os gregos inventaram a lógica, essa tecnologia de linguagem em que formas e conteúdos se relacionam numa estrutura que exige consistência e coerência interna. Daí, Aristóteles desenvolveria o seu famoso método de argumentação, como uma conexão entre afirmação e prova, isto é, um percurso dedutivo em que se lançam proposições e, em seguida, demonstra-se a verdade delas.

A articulação do método científico, nos albores da modernidade e do iluminismo, se deu por meio de uma dupla ruptura. Primeiro, com a religião e, especificamente, com o modo medieval de pensá-la. A verdade deixou de ser algo pressuposto ao texto e ao discurso do conhecimento e

comunicação, em alguns aspectos, parece ser justamente o inverso do que se questiona nas ciências de "epistemologia dura", como as naturais e biológicas.

Comum. \& Inf., v. 15, n. 2, p. 133-148, jul./dez. 2012 
passou a se situar depois deles. Em outras palavras, verdade não é o que se pressupõe, mas sim o que se pode concluir. Do ponto de vista político, isso significou um rompimento com o critério de autoridade (o texto seria verdadeiro porque quem o disse tem autoridade para dizer; na teologia, o próprio Deus), para uma admissão de que a autoridade estaria no método. A superação da religião como lugar da verdade vinculou-se, portanto, fortemente à preocupação com o método, cujo primeiro fundamento filosófico surgiu com Descartes e, a partir daí, movimentou todo o debate epistemológico até os dias de hoje.

A segunda ruptura foi a disjunção ocorrida dentro da própria articulação racionalista da modernidade: a separação entre filosofia e ciência ou, do ponto de vista epistemológico, entre a dedução e a indução. A assunção de uma vez por todas da indução como método da ciência se dá somente no início do século 20, com o rompimento de Karl Popper com o Círculo de Viena. A falseabilidade popperiana colocou abaixo a pretensão de verificabilidade. Ao situar a falseabilidade como o norte da pergunta científica, e a indução - um sofisma empirista - o seu modo de pensar, a ciência perdeu a capacidade de dizer a verdade e passou a trabalhar com as aproximações plausíveis, seja pelo cálculo de probabilidades, seja pelos gradientes de intensidade dos métodos qualitativos.

Concomitantemente a esse debate, houve no campo da filosofia a instauração da filosofia da linguagem, por Wittgenstein, que deslocou a verdade para o pantanoso e movediço terreno dos jogos de fala. Ele também efetuou a ruptura com a verificabilidade, no trânsito entre o Tractatus Logico-Philosophicus e o Investigações Filosóficas, quetrouxe consigoum importante desenvolvimento do pensamento epistemológico, com o reconhecimento que a filosofia e a ciência não são "representações" fiéis da realidade, e sim discursos sobre ela (WITTGENSTEIN, 2005 e 2005a). A verdade, então, entra em crise para sempre, seja dentro da visada pós-moderna, em que praticamente perde o sentido, ao converter-se em apenas fragmentos das disputas discursivas entre proposições todas elas efêmeras e precárias; seja no âmbito da modernidade tardia, onde assume de vez a relatividade dos processos linguageiros, concebida como o consenso possível entre sujeitos de fala que reivindicam para seus argumentos a validade das regras de interlocução.

A segunda crise das ciênciasé a crise das especializações.É interessante observar que o surgimento das especialidades propriamente científicas, decorrente da disjunção entre filosofia e ciência, é um fenômeno recente, na história do pensamento moderno. Até o século 18, a filosofia era o único referencial de unificação dos saberes disponíveis ou, segundo Foucault, "o sistema de comunicação dos saberes, uns em relação com os outros” (FOUCAULT, 1999, p. 214). Uma visão

Comum. \& Inf., v. 15, n. 2, p. 133-148, jul./dez. 2012 
meramente epistemológica das especializações disciplinares tende a percebê-la como uma mera separação de saberes, a partir de perguntas e teorizações específicas, que surgiriam por bipartição ou por inovações nas descobertas científicas. Nesse sentido, usualmente uma ciência surge do interior de outra, mais antiga e mais consolidada, como um movimento de superação, de desdobramento ou de ruptura.

Contudo, a visada da sociologia do conhecimento, iniciada com Thomas Kuhn, ampliou esse âmbito de análise, introduzindo questões de contexto e interesse nas próprias definições dos saberes científicos. Nesse sentido, como esclareceu Morin,

uma disciplina pode ser definida como uma categoria organizadora do conhecimento científico: ela institui a divisão e a especialização do trabalho, e responde à diversidade dos domínios que recobrem as ciências (MORIN apud GÓMEZ, 2005, p. 18).

Segundo Morin, é próprio de uma disciplina lutar por sua autonomia, seja por delimitação de suas fronteiras, seja pela constituição de uma linguagem própria, seja pelo desenvolvimento de técnicas que lhe sejam específicas, seja pela construção de conceitos e teorias (GÓMEZ, 2005).

O desdobramento do conhecimento em miríades de saberes especializados, estimulado pelas lutas políticas pela legitimidade e pela autonomia de cada um desses saberes, levou a articulação científica nos dias de hoje a uma enorme fragmentação. Trata-se de um vertiginoso processo de construção do conhecimento em que os cientistas passaram a saber cada vez mais de cada vez menos e, mergulhados na complexidade das especificidades, perderam praticamente todas as possibilidades de construírem teorias gerais ou mesmo integradas a saberes que eventualmente não adotem as mesmas linhas teóricas ou metodológicas.

É possível mesmo afirmar que as teorias gerais não apenas se tornaram impraticáveis, como, em certos círculos do pensamento epistemológico, ganharam um selo de suspeição. A eficácia das disciplinas, especialmente daquelas engajadas na produção das tecnologias, bem como a necessidade quase atávica de afirmação dos redutos disciplinares contra tudo aquilo que ameace suas fronteiras, conduziu à desconfiança e ao descrédito de qualquer articulação teórica com pretensões holísticas ou unificadoras. Como afirmaram ad nauseam os pós-modernos, passamos a viver o fim das grandes narrativas.

Entretanto, isso não impediu o surgimento de novos problemas, desta vez decorrentes da multiplicação das especialidades. Nesse sentido, podem ser apontados problemas internos à articulação científica e problemas externos à ciência. Entre os primeiros, é digno de nota o que Gómez denominou o problema da "certificação universal" dos critérios utilizados pelas agências

Comum. \& Inf., v. 15, n. 2, p. 133-148, jul./dez. 2012 
para definir prioridades nas dotações orçamentárias voltadas para a atividade científica. Segundo ela, estes são

problemas que surgem nos contextos da avaliação comparativa (conselhos nacionais de pesquisa, universidades), onde a definição das prioridades e a atribuição de excelência perpassam desde as grandes disciplinas e suas especialidades as áreas inter e transdisciplinares, as quais se configuram hoje não como soma e reunião integradora, mas como uma pluralidade de configurações geradas em torno de diversos parâmetros intertemáticos. Nesse contexto, a pressuposição de critérios de "certificação universal" só poderia expressar juízos preferenciais de excelência. Isso geraria uma tensão entre a regra apresentada como única e a polinomia das praticas cientificas, polinomia que existiria não só entre especialidades ou disciplinas, mas também no interior de uma mesma área, tal como entre a física teórica e a experimental. (...) Para Fuller (1988), existiria em todaprática cientifica uma "metaciência"implícita no formato de argumentação da disciplina, queintervém como premissa tácita da autoridade cientifica na resolução de controvérsias e conflitos. (GÓMES, 2005, p. 20)

Para além dessas questões de política científica, para cuja solução aparentemente prevalece mais a disputa política, com frágeis fundamentos epistemológicos, do que a conformação de parâmetros integradores, há também os problemas externos à ciência, decorrentes das exigências sociais direcionadas ao meio científico. Estes são, em geral, problemas de integração de teorias e metodologias, para fazer face a demandas da sociedade, e que se estruturam como desafios enfrentados com enorme dificuldade.

Um exemplo típico desse tipo de problema encontra-se na questão ecológica.Um simples intervenção voltada para a despoluição de um curso d'água precisa envolver, de forma cooperativa, as mais diferentes disciplinas científicas, dada a miríade de fatores intervenientes ao processo, que vão desde aqueles relacionados à química e à geografia das águas, até os problemas políticos, sociais e econômicos das populações e instituições envolvidas. A ecologia é um desses campos chamados interdisciplinares, que refletem uma forte demanda externa ao meio científico, e cujas teorizações e metodologias não têm como pertencerem a um único espaço disciplinar.

Arriscamo-nos a dizer que a comunicação é outro, desses campos, sem, contudo, uma demanda externa tão fortemente posicionada; mas, trataremos desse assunto mais tarde. Seja suficiente dizer, neste momento, que a crise das especialidades, caracterizada pela ausência de teorias integradoras dos conhecimentos especializados, seja porque inexiste esse interesse, seja por conta de impossibilidades epistemológicas ou metodológicas, constitui um espaço de falta que, não raro, acarreta distorções nas decisões de política científica e deixa sem resposta importantes demandas da sociedade.

Comum. \& Inf., v. 15, n. 2, p. 133-148, jul./dez. 2012 
A terceira crise é a crise social da ciência, que é o modo como denomino a suspeita, levantada por Boaventura Santos, de que a ciência não consegue atender a algumas das mais caras promessas da modernidade: a da justiça social, a da construção ética e a da solidariedade, racionalmente fundamentadas.

A ciência é hoje a construção cultural que mais prestígio desfruta, dentre todas aquelas que elegeram a verdade como fundamento de seus conteúdos. Seu prestígio é tamanho que o adjetivo "científico" passou a significar critério de autoridade de quaisquer proposições para as quais se queira garantir legitimidade social. Mesmo a conflitualidade de nascença da ciência com a religião, que, no princípio da modernidade, surpreendeu Galileu negando obviedades para não ser purificado nas fogueiras da Inquisição, hoje culmina em denominações religiosas buscando - muitas vezes honestamente - para si mesmas o status científico, a fim de garantirem perenidade e credibilidade para suas articulações mais ou menos dogmáticas. A ciência talvez seja a grande religião da contemporaneidade.

Evidentemente, essa situação de credibilidade exacerbada tem referenciais bastante claros e legítimos, decorrentes do que Boaventura Santos denominou como sendo o cumprimento excessivo de certas promessas da modernidade. A promessa de domínio e controle das forças naturais, bem como a de sua utilização nos sistemas de produção de riqueza, foram cumpridas exageradamente. $\mathrm{O}$ cotidiano da Humanidade foi de tal maneira invadido pelos produtos do conhecimento científico que ninguém hoje ousaria honestamente duvidar de alguma proposição científica, com a veemência como fizeram os paripatéticos, que, ante as evidências, afirmaram que o diabo havia dominado a luneta de Galileu.

Contudo, o déficit deixado pela modernidade, especialmente nos aspectos social e ético, constitui hoje o panorama de uma crise, que nasce das estruturas da própria condição moderna. Boaventura de Souza Santos percebe a modernidade a partir da tensão dialética entre dois pilares: o da regulação e o da emancipação. Para ele, o desenvolvimento contemporâneo das sociedades tem levado à absorção colonizadora do pilar da emancipação pelo da regulação, movimento para o qual a ciência tem cumprido papel fundamental.

A colonização gradual das diferentes racionalidades da emancipação moderna pela racionalidade cognitivo-instrumental da ciência levou à concentração das energias e das potencialidades emancipatórias da modernidade na ciência e na técnica (SANTOS, 2000, p. 55).

Comum. \& Inf., v. 15, n. 2, p. 133-148, jul./dez. 2012 
Ocorre que as promessas sociais e éticas do desenvolvimento científico deixaram um déficit, que constitui a geratriz do que neste artigo denominamos a "crise social da ciência", conformando hoje o que pode ser considerado o principal desafio da racionalidade científica contemporânea.O sociólogo português efetua uma síntese bastante elucidativa das consequências disso, que ele denomina a "hipercientificização do pilar da emancipação", ao enumerar que

a promessa da dominação da natureza, e do seu uso para o benefício comum da humanidade, conduziu a uma exploração excessiva e despreocupada dos recursos naturais, à catástrofe ecológica, à ameaça nuclear, à destruição da camada de ozono, e à emergência da biotecnologia, da engenharia genética e da consequente conversão do corpo humano em mercadoria última. A promessa de uma paz perpétua, baseada no comércio, na racionalização científica dos processos de decisão e das instituições, levou ao desenvolvimento tecnológico da guerra e ao aumento sem precedentes do seu poder destrutivo. A promessa de uma sociedade mais justa e livre, assente na criação da riqueza tornada possível pela conversão da ciência em força produtiva, conduziu à espoliação do chamado Terceiro Mundo e a um abismo cada vez maior entre o Norte e o Sul. Neste século morreu mais gente de fome do que em qualquer dos século anteriores, e mesmo nos países mais desenvolvidos continua a subir a percentagem dos socialmente excluídos, aqueles que vivem abaixo do nível de pobreza (o chamado 'Terceiro Mundo interior') (SANTOS, 2000, p. 56).

Ante esse quadro de crises, é imperioso indagar não apenas sobre o lugar da comunicação, no episódio das ciências, mas, também e sobretudo, sobre o lugar das pretensões epistemológicas dos estudiosos da comunicação, ante a crise epistemológica das ciências em geral.Evidentemente, trata-se de um esforço filosófico que demanda muito mais do que o que é cabível num ensaio, como este trabalho. Entretanto, talvez seja possível colocar aqui em discussão alguns dos indicativos que podem nos conduzir para um caminho produtivo e heurístico, nesse sentido.

\section{$2 \mathrm{O}$ enfrentamento comunicativo das crises das ciências}

Ante a crise das ciências, a comunicação no Brasil vive uma crise muito específica: a crise de sua própria afirmação, dentro de condições teóricas e metodológicas que a possam garantir como disciplina científica. Diante de perguntas aparentemente simples, como "O que é comunicação?”; “Quais as categorias definem o saber comunicacional como saber próprio?”; “Qual a especificidade do objeto de pesquisa da ciência da comunicação?”; e "Quais metodologias são específicas do objeto da ciência da comunicação?"; a resposta mais consistente de qualquer um de nós deve se situar entre o mero "não sabemos" ao difuso "há várias respostas para cada uma dessas indagações".

Comum. \& Inf., v. 15, n. 2, p. 133-148, jul./dez. 2012 
O lógico seria que, enquanto não tivéssemos respostas suficientemente claras para cada uma destas perguntas, ou ao menos para algumas delas, não há que se falar em uma ciência da comunicação. A definição de uma disciplina científica, contudo, como se disse neste trabalho, é uma formulação política muito mais definida pelo campo de forças formado pelos pesquisadores e instituições científicas, do que uma consequência epistemológica da racionalidade científica. Como deixa perceber Lopes (2003), no realismo cortante dos sociólogos, há um campo da comunicação no Brasil, porque existem pesquisadores, núcleos de pesquisa, faculdades e programas de pósgraduação em comunicação nas Universidades. O sociologismo de Pierre Bourdieu serve como uma luva para afirmarmos o campo pelo viés das movimentações sociais, mais do que pela qualidade teórica da produção científica.

Esse debate, porém, não perde o sentido, por conta da interpretação sociológica do desenvolvimento da formação e da pesquisa em comunicação. Ao contrário, tem passado crescentemente a se constituir um desafio para os pensadores da área - o que talvez seja uma conclusão possível do nível de aprovação que teve o GT Epistemologias da Comunicação, na última reclivagem feita pela Compós. O debate epistemológico, por tal razão, constitui hoje, senão o principal, um dos mais relevantes temas do campo científico da comunicação no Brasil. Certamente, por isso, pode-se afirmar que a comunicação é hoje um campo disciplinar em franco processo de afirmação e legitimação, no Brasil.

Entretanto, o esforço pela afirmação docampo remete a ciência da comunicação para uma contradição específica: a de afirmar uma disciplina num momento em que as disciplinas fracassam. E, como diz Rüdiger (2007), criar uma disciplina de uma in-disciplina, no reconhecimento da interdisciplinaridade de nascença que caracteriza o campo da comunicação.Sua visada, contudo, não é a da mera interdisciplinaridade do campo, e sim de sua condição de refém de situações não científicas, que extrapolam o seu âmbito de ação, mas que o condicionam fortemente. Nesse sentido, afirma ele que

intelectualmente, a comunicação, reiteramos, não é uma disciplina, mas um campo de saber, que se revela cada vez mais indisciplinado. Os saberes que pretendiam estudá-lo com atitude metódica estão sendo tragados pelo seu redemoinho, cuja força não se origina da reflexão teórica, mas antes das engrenagens da economia de mercado, da atividade publicística e do desenvolvimento tecnológico de nossa civilização maquinística (RÜDIGER, 2007, p. 37).

Por esta razão, Rüdiger parece banir a própria ideia da discussão epistemológica. Para ele,

Comum. \& Inf., v. 15, n. 2, p. 133-148, jul./dez. 2012 
sendo assim, a preocupação com a epistemologia da comunicação só pode ser vista como ordenadora de uma missão historiográfica e como atividade carregada de nostalgia por uma era passada. Quem se esforça em defini-la de acordo com esse critério, precisa perceber que se empenha em um campo que, paradoxalmente, impõe-se como eixo do mundo às custas do abandono da reflexão epistêmica (RÚDIGER, 2007, p. 37).

Pensamos que a análise de Rüdiger, embora se ancore em evidências de natureza política e econômica, termina por assumir um posicionamento contrafático. Afinal, o que parece estar ocorrendo dentro do campo da comunicação no Brasil é justamente o contrário: há um crescente interesse pelo debate epistemológico. E é nessa perspectiva que este trabalho se inscreve.

A compreensão deste texto é que a formação de um campo científico não é nem pode ser tão somente um problema político ou sociológico, embora tais referenciais sejam importantes para explicar as condições materiais de produção e reprodução do campo e possam, como em Rüdiger, oferecer espaços para a denúncia epistemológica da carência da crítica teórica, indispensável para consolidação científica do campo. Não bastam as instituições e os recursos em pesquisa para garantirem a formação de um campo científico: é preciso que tais condições sejam capazes de garantir uma construção teórica compatível com a alimentação do campo com indagações específicas que circunscrevam a área. Isso, contudo, é igualmente contraditório, já que as especialidades não dão conta dos problemas emergentes.

Eis porque o debate sobre a especificidade da comunicação passa pelo debate das crises das ciências. Não sendo e, talvez, nem podendo, nem devendo ser uma disciplina científica, stricto sensu, este trabalho levanta a hipótese de que o campo da comunicação provavelmente traga consigo algumas das condições específicas para o enfrentamento daquelas crises. Em outras palavras, em sua fragilidade talvez esteja sua maior força. Há peculiaridades interessantes no campo da comunicação, que podem definir o modo como este campo pode enfrentar as diferentes crises da ciência. Senão vejamos.

A crise da verdade, como vimos, caracteriza-se pelo fim das certezas e dos metarelatos, que culminaram na admissão popperiana de que a ciência não é senão o lugar da incerteza, da falseabilidade, da busca eterna pela verdade, sem a perspectiva de encontrá-la, senão provisoriamente. A verdade não passa de um valor encontrável - ou não - na linguagem, em proposições, cujo sentido poderá sempre ser posto em causa, seja pela exigência de referências no mundo objetivo, seja pela presença da discordância no mundo intersubjetivo, seja pelo surgimento de desconfianças fundadas, no mundo subjetivo.

Comum. \& Inf., v. 15, n. 2, p. 133-148, jul./dez. 2012 
Ante a crise da verdade, a comunicação pode assumir duas visadas, ambas produtivas, do ponto de vista epistemológico. A primeira, de natureza situacional,é de que a relativização da verdade situa o campo da comunicação exatamente no meio do furacão dessa crise, pois é dessa relativização, por meio da qual o campo da comunicação se vê entrecortado por outras disciplinas científicas, que o campo se alimenta. Talvez até a carência de reflexão teórica, identificada por Rüdiger, signifique justamente isso: a questão da verdade na comunicação ultrapassa os limites do próprio campo, adquirindo sentidos desencontrados nos âmbitos sociais e de mercado com os quais o campo se relaciona.

A segunda visada, de natureza filosófica, é deque, com a virada linguageira de Wittgenstein, o problema da verdade se tornou um problema de comunicação. Aliás, existem precedentes nos âmbitos filosófico e epistemológico nesse sentido. Vem dos filósofos do discurso, como Habermas e Appel, tanto o reconhecimento do caráter discursivo da ciência, quanto a definição comunicativa de verdade, como consenso entre os especialistas.

...o consenso dos especialistas fundamenta a verdade da decisão a que eles tenham chegado. Mas, ao mesmo tempo, é o fato de que todos eles alcancem um consenso acerca desses assuntos que tranqüiliza as pessoas comuns acerca de serem eles, efetivamente, especialistas e, como tais, titulares de um mandato tácito para declarar a verdade consensual dessas proposições cujo sentido escapa à maioria das pessoas. Dá-se entre eles, nos assuntos de sua especialidade, aquilo que se dá com toda gente quando se trata de fatos triviais, caso em que a verdade das proposições se fundamenta no consenso universal dos percipientes.Em ambas as circunstâncias o consenso sepretende verdadeiro, e não há outro critério para provar sua verdade senão a ausência de objeção a essa pretensão (ROCHA, 2011, p. 25).

Evidentemente, a ideia de verdade como produto de um tipo de comunicação - a que resulta num consenso - conduz a perspectiva da construção científica para o fértil campo da ética. Um campo científico é, pois, aquele em que os pares conseguem se entender e de tal forma que praticam entre si de modo suficiente a racionalidade comunicativa, com a assunção das pretensões de validade da ação comunicativa (inteligibilidade, verdade, veracidade e retidão normativa) até se atingir os consensos possíveis - que são relativos e frágeis, na medida em que duram apenas enquanto perdurar o consenso do qual se trata.

Uma das consequências desse modo de pensar foi a revolucionária leitura do método, feita por Boaventura Santos, para quem "os métodos científicos são argumentos cuja sequência e técnica de apresentação são da competência do cientista”. A ideia de método como argumento aprofunda a

Comum. \& Inf., v. 15, n. 2, p. 133-148, jul./dez. 2012 
responsabilidade do cientista, na proclamação da verdade científica; converte os pares em auditório especializado ou de referência; e lança a produção da verdade ao jogo comunicativo e a seus resultados (consensuais).

O corolário de tal reflexão é, sem dúvida, de que uma epistemologia da ciência, nesses parâmetros, tem que ser, obrigatoriamente, uma teoria do conhecimento como comunicação.

Uma reflexão semelhante pode ser aplicada à crise das especializações. O modo como a comunicação se inscreve nesta crise é bastante peculiar: a conformação prática do campo se situa em algum lugar entre não conseguir e não pretender adotar as regras e condições de uma disciplina científica. Não se consegue talvez porque a formação dentro dos cursos e faculdades trabalha ainda com uma formação teórica bastante rasteira, na medida em que visa em grande parte a formação técnica, decorrendo isso em déficit na formação de professores, pesquisadores e pensadores. Ao contrário de outras disciplinas das ciências sociais, a área da comunicação não busca formar teóricos ou metodólogos, e sim profissionais aptos a atender certas demandas empresariais no uso da comunicação como tecnologia especializada de linguagem. E não pretende certamente porque o esforço de pesquisa do campo se inscreve, desde o princípio, num panorama de complexidade do objeto que, por um lado, não permite acorrer a apenas uma explicação teórica, e, por outro, não alcança uma definição precisa do que seja o objeto, em sua especificidade.

Essa tensão entre a capacidade e a viabilidade configura ao mesmo tempo a fragilidade e a possibilidade do campo da comunicação no enfrentamento da crise das especializações. Fragilidade, no sentido de que é necessário que haja uma política específica de aprimoramento da formação no interior do campo, a fim de que se produza uma massa crítica em melhores condições para fazer o necessário enfrentamento dos problemas teóricos, epistemológicos e metodológicos. E possibilidade porque, na verdade, a interação entre as ciências, indispensável para enfrentar a crise das disciplinas, se dá por comunicação.

Pode-se, por isso, afirmar que é de natureza comunicativa a crise das especializações. Como ciência, a comunicação é interdisciplinar e, portanto, tem seu modo próprio de romper com a crise ao não se conformar como campo disciplinar autóctone e assumir de vez a perspectiva do campo de saberes, próximo ao que sugere Rüdiger. Mas, não apenas isso. A interpretação comunicativa da crise das ciências apenas se completa naquilo que se configura como possibilidade no enfrentamento da crise social da ciência.

A crise social da ciência, enunciada, nos termos deste trabalho, a partir de Boaventura de Souza Santos, encontra neste autor a proposição básica para sua superação. Após enunciar esta crise

Comum. \& Inf., v. 15, n. 2, p. 133-148, jul./dez. 2012 
como o esgotamento do modelo platônico, de separação entre doxa e episteme, ou entre a opinião e o saber, o autor português defendeu uma segunda ruptura epistemológica, configurada como sendo a ruptura com a primeira ruptura, ou seja, a reconciliação entre os saberes sistematizados da filosofia e da ciência com o senso comum.

O modo como Santos efetua esta proposição é, no mínimo, original. A sua pretensão é superar, a um só tempo,o preconceito contra a formação da opinião - hoje conceito indispensável aos processos democráticos - e ensejando o retorno - comunicativo, é preciso que se destaque - da ciência em direção aos povos, a fim de comprometer-se com a construção de um novo senso comum: emancipatório, bem informado e participativo.

Para isso, ele propõe que esse novo senso comum seja constituído de três dimensões: a dimensão ética, de promoção da solidariedade; a dimensão política, de promoção da participação; e a dimensão estética, de promoção do prazer. Nesta conjunção, deve ocorrer, em sua visão, uma inversão epistemológica, que passa da predominância da epistemologia (e, por conseguinte, dos critérios metodológicos) das ciências naturais sobre as demais ciências para uma priorização neste mesmo sentido das ciências sociais. "Todas as ciências são ciências sociais", proclama ele (SANTOS, 2000, p. 89).

A visão de Boaventura Santos talvez seja excessivamente sociológica, ao abordar o conhecimento. Às três dimensões do processo de formação de um senso comum emancipatório, sem dúvida que faltam as dimensões cognitiva e comunicativa. A primeira, que garanta o processo de construção do conhecimento e a segunda, que se torne o modo pelo qual as demais dimensões poderiam se relacionar. Afinal, a conexão entre o saber sistematizado e o senso comum, sem a perda das conquistas do primeiro nem a continuidade da exclusão do segundo, só pode ser feita comunicativamente. Trata-se de uma ciência que dialoga, cuja teorização pode ser feita, sim, a partir da perspectiva retórica, como faz Boaventura Santos, mas não precisa deixar de lado outras visadas, dentro da perspectiva de uma teoria comunicativa do conhecimento.

Destarte, qualquer seja a saída para a crise social da ciência, ela terá de ser comunicativa.

Eis porque a busca pela construção de uma epistemologia da comunicação não se remete tão somente à produção de uma mera disciplina científica, mas sim ao enfrentamento da própria crise da ciência. Interdisciplinar, orientada aos estudos da circulação da linguagem e comprometida com os processos de produção e reprodução da democracia, do conhecimento e da opinião pública, a comunicação é a ciência fundamental do mundo contemporâneo. O conceito de comunicação é,

Comum. \& Inf., v. 15, n. 2, p. 133-148, jul./dez. 2012 
portanto, central para o próprio debate epistemológico, qualquer seja a linha que se pretenda seguir, sendo, pois, de interesse de todas as ciências.

E, por fim, ante a pergunta fundamental do debate epistemológico atual, nocampo, isto é, frente à pergunta sobre “o que é, afinal, o que denominamos comunicação, em nossos estudos?”, a resposta epistemológica que podemos neste momento dar, sem a pretensão de exaustividade definidora, é que, em meio às possibilidades existentes: é comunicação a ética procedimental dos vínculos democráticos, por meio de cuja teorização torna-se possível enfrentar a crise das disciplinas, a crise da verdade e a crise social das ciências. É também comunicação é aquilo que integra sem unificar e gerencia sem resolver o desequilíbrio dos diferentes saberes, linguagens e experiências humanas. E é comunicação ainda o modo pelo qual a experiência se torna linguagem, a linguagem se converte em saber e o saber se concretiza em novas experiências, tornando possível o trânsito das ideias e dos sentidos.

Artigo submetido em 09/11/2012 e aceito em 16/01/2013.

\section{Referências}

ALBUQUERQUE, Afonso de. Os desafios epistemológicos da comunicação mediada por computador. Revista Fronteiras, Estudos Midiáticos. São Leopoldo: Unisinos, 2002.

BRAGA, José L. Os estudos de interface como espaço de construção do campo da comunicação. São Bernardo do Campo-SP: GT Epistemologia da comunicação Compós, 2004. FOUCAULT, Michel. Em defesa da sociedade. São Paulo: Martins Fontes, 1999.

GÓMEZ, Maria Nélida G. de. A vinculação dos conhecimentos: entre a razão mediada e a razão leve. Liinc em Revista, v. 1, n. 1, p. 16-37, mar. 2005.

HABERMAS, Jürgen. Teoría de laacción comunicativa. Madrid: Taurus, 1989. 3 v. LOPES, Maria I. V. de. Sobre o estatuto disciplinar do campo da comunicação. In: Epistemologia da comunicação. São Paulo: Loyola, 2003. p. 277-293.

POPPER, Karl. A lógica da pesquisa científica. São Paulo: Cultrix, 2000.

ROCHA, Alexandre S. da. Cientificidade e consenso: esboço de uma epistemologia a partir da Teoria Consensual da Verdade de Jürgen Habermas. Disponível em: <http://files.alexdarocha. webnode.com.br/200000022-373cd37971/Cientificidade.pdf>. Acesso em: 21 set. 2011.

RÜDIGER, Francisco. A comunicação no saber pós-moderno: crítica, episteme e epistemologia. In: FERREIRA, Jairo. Cenários, teorias e epistemologias da comunicação. Rio de Janeiro: E-papers, 2007. p. 25-40.

Comum. \& Inf., v. 15, n. 2, p. 133-148, jul./dez. 2012 
SANTOS, Boaventura de S. A crítica da razão indolente: contra o desperdício da experiência. São Paulo: Cortez, 2000.

SIGNATES, Luiz. Epistemologia da comunicação na democracia: a centralidade do conceito de comunicação na análise dos processos políticos. Porto Alegre: GT Epistemologias da Comunicação/20 Compós, 2011.

SIGNATES, Luiz. O problema não é só nosso: um estudo sobre a fragilidade epistemológica das teorias sociais para dar conta da problemática da comunicação. Goiânia: Inédito, 2001.

THOMPSON, John. A mídia e a modernidade. Petrópolis: Vozes, 2002.

WITTGENSTEIN, Ludwig. Investigações filosóficas. Petrópolis: Vozes, 2005a.

WITTGENSTEIN, Ludwig. Tractatuslogico-philosophicus. Madrid: Alianza, 2005.

Comum. \& Inf., v. 15, n. 2, p. 133-148, jul./dez. 2012 